\title{
Glioma Lysate Vaccine GBM6-AD
}

National Cancer Institute

\section{Source}

National Cancer Institute. Glioma Lysate Vaccine GBM6-AD. NCI Thesaurus. Code C139000.

An allogeneic cell lysate-based vaccine derived from the glioma stem cell line GBM6-AD, which was isolated from the brain tumor of a patient diag nosed with glioblastoma multiforme (GBM), with potential immunostimulatory and antineoplastic activities. Upon subcutaneous administration, the glioma lysate vaccine GBM6-AD exposes the immune system to an undefined amount of glioma-associated antigens (GAAs), and stimulates the immune system to mount a specific anti-tumoral, cytotoxic T-lymphocyte (CTL)mediated response against the GAA-expressing cells, resulting in glioma cell lysis. 